\section{Discussion}

These studies show that patients on regular dialysis who are iron deficient will respond to oral iron therapy, and also that in these patients the state of the body's iron stores still influences absorption. The marrow iron stores are the most valuable guide to the need for treatment with iron and this confirms the observations of Edwards et al. (1970). The level of absorption in our iron-deficient patients did not approach those reported by Escbach et al. (1970). The two groups of patients may not be comparable, but their finding that iron absorption was entirely compatible with their patients' requirements was not confirmed in this study. The failure of the patients in the present study to replenish their marrow iron stores suggests that prolonged therapy may be required by those on regular renal dialysis.

Utilization of iron for haemoglobin formation occurred at the rate seen in the studies on intravenous iron by Carter $e t$ al. (1969), but there is no evidence that parenteral iron only was capable of being utilized. Parenteral iron is not more effective, and unless the requirement is carefully calculated and the result of treatment assessed from the marrow iron serious overload may develop

The rate of blood loss varied considerably in these patients, and individuals could show pronounced variation in mean loss at dialysis in successive periods. The patient with the insidious loss of from 5 to $30 \mathrm{ml}$ of blood per dialysis is most at risk as this may not be appreciated. It is in this group that prolonged oral iron therapy would be beneficial.

We would like to acknowledge the help of Sister A. Dobson and Sister H. de L. Nichols at the Renal Dialysis Centre; Mr. L. Millbank, of the department of haematology, St. Bartholomew's Hospital, for his help with the folate estimations; and Mr. N. K.
Gupta and Mrs. A. Stringer, of the physics department and radiotherapy department respectively at the Royal Marsden Hospital, Sutton. We would also like to thank Mr. P. J. Cull and Mr. W. D. Tredinnick, of the department of medical illustration, St. Bartholomew's Hospital.

Requests for reprints should be sent to Dr. J. S. Malpas.

\section{References}

Boender, C. A., and Verloop, M. C. (1969). British fournal of Haematology, 17,45

Brozovich, B. (1971). In press.

Brozovich, B., and Copestake, J. (1969). Fournal of Clinical Pathology, 22 605.

Carter, R. A., Hawkins, J. B., and Robinson, B. H. B. (1969). British Medical fournal, 3, 206.

Cottrall, M. F., Stringer, A. M., and Trott, N. G. (1968). Radioaktive Isotope in Klinik und Forschung, 8, 122. (Urban and Schwarzenberg, Munich)

Cottrall, M. F., and Trott, N. G. (1971). Radioaktive Isotope in Klinik und Forschung, 9, 161. (Urban and Schwarzenberg, Munich)

Crockett, R. E., et al. (1967). Proceedings of the European Dialysis and Transplant Association, 4, 17.

Curtis, J. R., et al. (1969). Quarterly fournal of Medicine, 38, 49.

Dacie, J. V., and Lewis, S. M. (1968). Practical Haematology, 4th edn. London, Churchill.

Edwards, M., Pegrum, C. D., and Curtis, J. R. (1970). Lancet, 2, 491.

Escbach, J. W., Cook, J. D., and Finch, C. A. (1970). Clinical Science, 38,

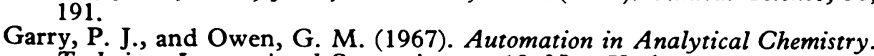
Technicon International Symposium, p. 18. New York.

Holt, J. M., Mayet, F. G. H., Warner, G. T., and Callender, S. T. (1967) British Medical Fournal, 4, 86.

Holt, J. M., Mayet, F. G. H., Warner, G. T., Callender, S. T., and Gunning, A. J. (1968). British Medical Fournal, 3, 22.

Millbank, L., Davis, R. E., Rawlings, M., and Waters, A. H. (1970). fournal of Clinical Pathology, 23, 54 .

Najean, Y., and Ardaillou, N. (1963). Nouvelle Revue française d'Hématologie, 3, 82.

Rath, C. E., and Finch, C. A. (1948). Journal of Laboratory and Clinical Medicine, 33, 81.

\title{
Effect of Measles Vaccination on Incidence of Measles in the Community
}

\author{
IAN SUTHERLAND, P. M. FAYERS
}

British Medical fournal, 1971, 1, 698-702

\section{Summary}

A study of the effect of measles vaccination on the incidence of the disease in eight separate areas of England and Wales was begun in 1966. It showed an inverse association between the proportion of children vacsinated and the incidence of measles in the area in the following year, but measles epidemics occurred in several of the areas in subsequent years, despite continuing vaccinations.

Measles vaccination was introduced on a large scale in Britain in 1968. Analysis of the notification and vaccination statistics shows that the vaccination of about $10 \%$ of the child population (under 15 years) in 1968 sufficed to "replace" the measles epidemic which had bcen expected in the period October 1968 to Sepiember 1959 by a low incidence of the disease, typical of that in previous "interepidemic" years. Further, the effect of the vaccinations was to prevent the develop-

M.R.C. Statistical Research and Services Unit, London WC1E 6AS

IAN SUTHERLAND, M.A., D.PHIL., Director

P. M. FAYERS, B.SC., Scientific Staff Member ment of natural measles in susceptible unvaccinated children as well as in the vaccinated subjects. Thus the number of immune subjects in the community was increased by the vaccinations, but as a result there was a reduction in the number of subjects who acquired immunity from natural measles. These opposed results can therefore explain why vaccination may be effective in the community for only a year or two, though vaccination protects the individual for much longer.

It is estimated that a continuing vaccination rate of $\mathbf{4 0}$ to $50 \%$ of the children born each year would be necessary to replace the regular biennial measles epidemics in Britain by a continuous endemic incidence, and might perhaps lead to the disappearance of the disease without a further major epidemic, but that a continuing vaccination rate of 80 to $90 \%$ of children born each year would then be necessary to prevent its reintroduction. The long-term control of measles by vaccination will thus probably prove more difficult than for any other infectious disease.

\section{Introduction}

At the instigation of the M.R.C. Measles Vaccines Committee a study was begun in 1966 of the effect of measles vaccina- 
tion on the incidence of the disease in the community. The medical officers of health of eight areas (Bedford, Bristol, Cardiff, Kingston upon Hull, Leicestershire, Newcastle upon Tyne, Oxford, and Southampton) elected to take part. In Bristol, Cardiff, Leicestershire, and Southampton the vaccination campaign was concentrated initially on preschool children, but in the other four areas all children up to about 10 years of age were eligible for vaccination.

Measles vaccination was started in all the areas between June and August 1966. The vaccination schedule in six of the areas consisted of a single dose of live measles vaccine (Glaxo), but in Bristol and Cxford a dose of killed measles vaccine (Pfizer) was given a month before a dose of live vaccine (Wellcome). (From January 1958 in Bristol and from June 1968 in Oxford the preliminary dose of killed vaccine was omitted, and in March 1969 both areas changed from Wellcome to Glaxo live vaccine.)

Each medical officer of health submitted relevant returns for his area for 1966, for the first quarter of 1967, and thereafter six-monthly. The information comprised the numbers of measles vaccinations performed, the total numbers of cases of measles notified, and the numbers of notifications in vaccinated subjects, all subdivided by age and sex. These data have been analysed in conjunction with the Registrar General's estimates of the size of the population of the various areas.

\section{Effects of Measles Vaccinations}

\section{SEVEN AREAS IN ENGLAND AND WALES FROM 1966}

The findings from 1966 to 1969 in seven of the areas are summarized in Table I. (Because of local difficulties it was possible to vaccinate only a small proportion of the Leicestershire children; in addition, returns could not be made for the same periods of time as those for the other areas. The findings for Leicestershire have consequently been omitted from this report.) The areas are arranged in Table $I$ in decreasing order of intensity of vaccination at ages $0-4$ years

TABLE I-Measles in 1966-9 in Seven Areas in England and Wales where Measles Vaccination began in 1966

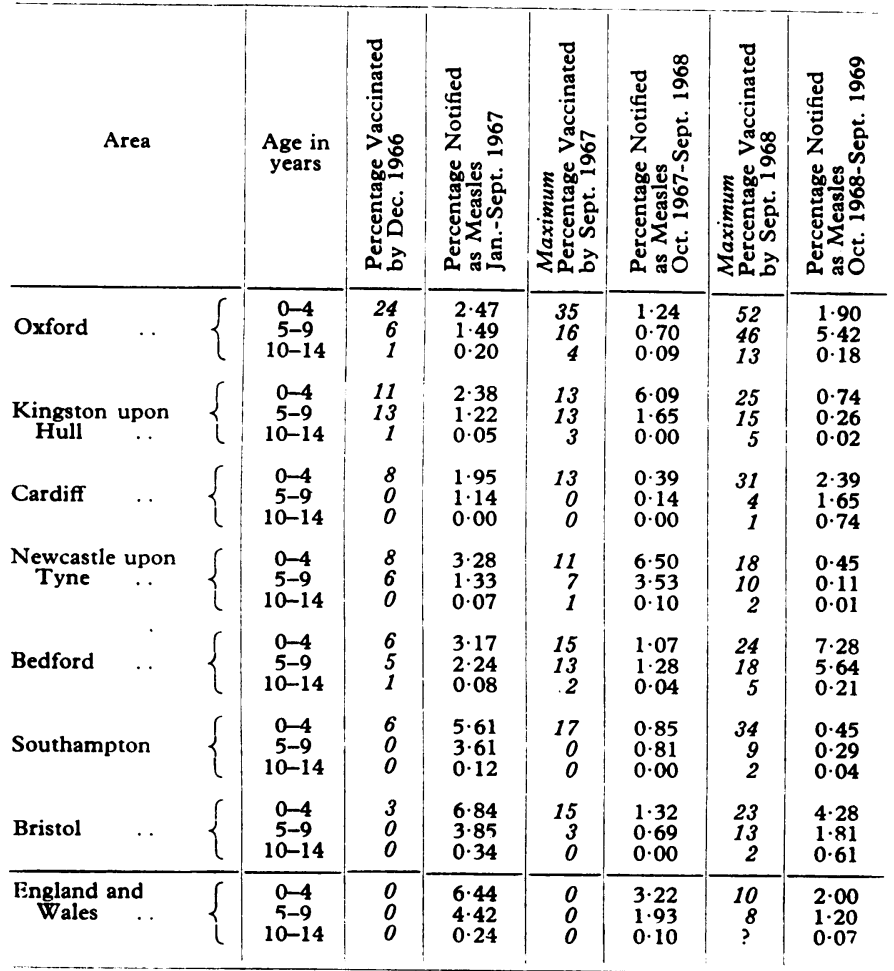

during 1966. Comparative figures for the whole of England and Wales are also given.

In the first nine months of 1967 there was an association between the extent of previous vaccination and the incidence of notified measles. The areas with the largest proportions of vaccinated children at ages 0-4 years (Oxford, Hull, and Cardiff) had the lowest incidence of measles in this age group, and those with the smallest proportions (Southampton and Bristol) had the highest incidence. In these last two areas the rate was similar to that in the whole country. The incidence of measles at ages 5-9 years showed a similar association with the extent of vaccination at these ages.

By September 1967 the proportions of children vaccinated were probably substantially larger in most of the areas than at the end of 1966, but the figures in Table I almost certainly overestimate the true position because they make no allowance for vaccinated children who had moved out of the area since being vaccinated. Nevertheless, it is clear that the relationship between intensity of vaccination and incidence of measles no longer applied in 1967-8. In the first nine months of 1967 none of the areas except Bristol (at ages 0-4) had had a measles incidence in excess of that in the country as a whole. In the year October 1967 to September 1968, however, which was an "interepidemic" year in the country as a whole, measles reached epidemic levels both in Hull (at ages 0-4) and in Newcastle (at ages 0-4 and 5-9), despite the previous vaccinations. Again in the following year, October 1968 to September 1969, there was a substantial excess measles incidence over that in the whole country, not only in Bedford (at ages 0-4 and 5-9) and Bristol (at ages 0-4 and 5-9), two of the areas in which relatively small proportions of children were vaccinated in 1966 and subsequently, but also in Oxford (at ages 5-9) and Cardiff (at ages 0-4 and 5-9), where there were high vaccination rates and a low incidence of measles in 1966-7. Similarly, in Nottingham (Parry and Ducksbury, 1970) the measles vaccinations given in 1968 appeared to suppress the epidemic of measles expected in 1969, but this was followed, despite some further vaccinations, by an epidemic in 1970 .

It would therefore seem that, in community terms, the benefits of measles vaccination may be limited to the epidemic immediately following the introduction of the vaccine.

\section{THROUGHOUT ENGLAND AND WALES FROM 1968}

In order to resolve this apparent paradox of an individual protection, both from the live and from the killed/live vaccination schedule, which has now been shown to last for at least five years (M.R.C. Measles Vaccines Committee, 1971), and a communal protection which may last no more than a year, it is instructive to look at the pattern of measles in England and Wales as a whole, where measles vaccination started on a substantial scale during 1968 , two years later than in the eight areas referred to above. By the end of 1968 over 700,000 vaccinations of children against measles had been made in the whole country (Report, 1968). The notifications of measles from 1966 to 1969 are summarized at the foot of Table I; they are analysed in greater detail in Table II.

Data for the three years 1966-7, 1967-8, and 1968-9 (October to September in each case, because this corresponds to the usual seasonal pattern of measles) are given in Table II. The first of these was an epidemic year for measles, the second an interepidemic year, and another major epidemic was expected in the third year. (The recent pattern has been an epidemic regularly in alternate years.) The first three lines of data for each year record the numbers of cases of measles notified in different age groups, the estimates of the population totals in which they occurred, and the percentage notified as measles (this is less than the true attack rate because of deficiencies in notifications). The notification rates were much lower at each age in 1967-8 than in 1966-7, and slightly lower still in 1968-9. 
TABLE II-Measles in England and Wales 1966-9

\begin{tabular}{|c|c|c|c|c|c|c|c|c|c|c|c|c|}
\hline \multirow{2}{*}{ Year } & & & & & & \multicolumn{7}{|c|}{ Age in Years } \\
\hline & & & & & & $0-$ & $1-$ & $2-$ & $3-$ & 4 & $5-9$ & $10-14$ \\
\hline \multirow[t]{2}{*}{ Oct. 1966-Sept. 1967} & $\begin{array}{l}\text { Measles notifications } \\
\text { Pop. (thousands, mid-1966) } \\
\text { Percentage notified as measles }\end{array}$ & $\begin{array}{l}\cdots \\
\cdots\end{array}$ & $\begin{array}{l}\cdots \\
\cdots\end{array}$ & $\begin{array}{l}. \\
\cdots\end{array}$ & $\begin{array}{l}\cdots \\
\cdots \\
\cdots\end{array}$ & $\begin{array}{r}22,818 \\
839 \cdot 5 \\
2 \cdot 7\end{array}$ & $\begin{array}{r}66,578 \\
849 \cdot 0 \\
7 \cdot 8\end{array}$ & $\begin{array}{r}85,053 \\
842 \cdot 7 \\
10 \cdot 1\end{array}$ & $\begin{array}{r}88,665 \\
826 \cdot 9 \\
10 \cdot 8\end{array}$ & $\begin{array}{r}85,309 \\
809 \cdot 1 \\
10 \cdot 5\end{array}$ & $\begin{array}{r}213,980 \\
3,634 \cdot 0 \\
5 \cdot 9\end{array}$ & $\begin{array}{r}9,565 \\
3,255 \cdot 9 \\
0 \cdot 3\end{array}$ \\
\hline & $\begin{array}{l}\text { (a) Estimated percentage susceptible } \\
\text { Percentage of susceptibles notified }\end{array}$ & $\begin{array}{ll}\text { (Oct. } \\
\cdots\end{array}$ & $\begin{array}{l}966) \\
\cdots\end{array}$ & .. & $\because$ & $\begin{array}{r}50 \cdot 0 \\
5 \cdot 4\end{array}$ & $\begin{array}{r}98 \cdot 6 \\
7 \cdot 9\end{array}$ & $\begin{array}{l}90 \cdot 6 \\
11 \cdot 1\end{array}$ & $\begin{array}{l}79 \cdot 3 \\
13 \cdot 6\end{array}$ & $\begin{array}{l}69 \cdot 9 \\
15 \cdot 0\end{array}$ & $\begin{array}{l}44 \cdot 5 \\
13 \cdot 3\end{array}$ & $\begin{array}{r}20 \cdot 6 \\
1.5\end{array}$ \\
\hline \multirow[t]{2}{*}{ Oct. 1967-Sept. 1968} & $\begin{array}{l}\text { Measles notifications } \\
\text { Pop. (thousands, mid-1967) } \\
\text { Percentage notified as measles }\end{array}$ & . & $\begin{array}{l}\cdots \\
\cdots \\
\end{array}$ & $\because$ & $\begin{array}{l}\cdots \\
\cdots \\
\cdots\end{array}$ & $\begin{array}{r}9,874 \\
828 \cdot 3 \\
1 \cdot 2 \\
\end{array}$ & $\begin{array}{r}26,570 \\
835 \cdot 3 \\
3 \cdot 2 \\
\end{array}$ & $\begin{array}{r}32,290 \\
845 \cdot 9 \\
3 \cdot 8 \\
\end{array}$ & $\begin{array}{r}34,030 \\
840 \cdot 2 \\
4 \cdot 1 \\
\end{array}$ & $\begin{array}{r}31,677 \\
824 \cdot 5 \\
3 \cdot 8\end{array}$ & $\begin{array}{r}72,177 \\
3,747 \cdot 0 \\
1 \cdot 9\end{array}$ & $\begin{array}{r}3,378 \\
3,283 \cdot 9 \\
0 \cdot 1\end{array}$ \\
\hline & $\begin{array}{l}\text { Estimated percentage susceptible (C) } \\
\text { Percentage of susceptibles notified }\end{array}$ & $\begin{array}{ll}\text { ct. } 196 \\
. .\end{array}$ & 7) & $\because$ & $\because$ & $\begin{array}{r}50 \cdot 0 \\
2 \cdot 4 \\
\end{array}$ & $\begin{array}{r}94.5 \\
3.4 \\
\end{array}$ & $\begin{array}{r}83 \cdot 3 \\
4 \cdot 6 \\
\end{array}$ & $\begin{array}{r}74 \cdot 1 \\
5 \cdot 5 \\
\end{array}$ & $\begin{array}{r}62 \cdot 6 \\
6 \cdot 1\end{array}$ & $\begin{array}{r}40 \cdot 6 \\
4 \cdot 7\end{array}$ & $\begin{array}{r}18 \cdot 6 \\
0.5\end{array}$ \\
\hline \multirow[t]{3}{*}{ Oct. 1968-Sept. 1969} & $\begin{array}{l}\text { Measles notifications } \\
\text { Pop. (thousands, mid-1968) } \\
\text { Percentage notified as measles }\end{array}$ & $\begin{array}{l}\cdots \\
\cdots \\
\cdots\end{array}$ & $\begin{array}{l}\cdots \\
\cdots \\
\cdots\end{array}$ & $\begin{array}{l}\cdots \\
\cdots \\
\therefore\end{array}$ & $\begin{array}{l}\cdots \\
\cdots \\
\cdots\end{array}$ & $\begin{array}{r}7,670 \\
808 \cdot 3 \\
0.9 \\
\end{array}$ & $\begin{array}{r}19,084 \\
829 \cdot 1 \\
2 \cdot 3 \\
\end{array}$ & $\begin{array}{r}22,798 \\
834 \cdot 0 \\
2 \cdot 7 \\
\end{array}$ & $\begin{array}{r}24,214 \\
344 \cdot 9 \\
2 \cdot 9 \\
\end{array}$ & $\begin{array}{r}24,831 \\
839 \cdot 4 \\
3 \cdot 0\end{array}$ & $\begin{array}{r}54,076 \\
3,863 \cdot 0 \\
1 \cdot 4\end{array}$ & $\begin{array}{r}2,909 \\
3,349 \cdot 1 \\
0 \cdot 1\end{array}$ \\
\hline & $\begin{array}{l}\text { Vaccinated (thousands end-1968) } \\
\text { (b) Percentage vaccinated } \quad \ldots\end{array}$ & $\begin{array}{l}\cdots \\
\cdots\end{array}$ & $\ldots$ & $\therefore$ & . & $\begin{array}{l}3.4 \\
0.4\end{array}$ & $\begin{array}{r}103 \cdot 8 \\
12 \cdot 5\end{array}$ & $\begin{array}{r}112 \cdot 7 \\
13 \cdot 5\end{array}$ & $\begin{array}{l}98 \cdot 3 \\
11 \cdot 6\end{array}$ & $\begin{array}{l}87 \cdot 6 \\
10 \cdot 4\end{array}$ & $\begin{array}{r}313 \cdot 3 \\
8 \cdot 1\end{array}$ & $?$ \\
\hline & $\begin{array}{l}\text { *Estimated percentage susceptible ( } \\
\text { Percentage of susceptibles notified }\end{array}$ & $\begin{array}{ll}19 \\
\ldots\end{array}$ & 58) & $\because$ & $\therefore$ & $\begin{array}{r}49 \cdot 6 \\
1.8 \\
\end{array}$ & $\begin{array}{r}86 \cdot 1 \\
2 \cdot 7 \\
\end{array}$ & $\begin{array}{r}77 \cdot 1 \\
3 \cdot 5 \\
\end{array}$ & $\begin{array}{r}67 \cdot 7 \\
4 \cdot 3 \\
\end{array}$ & $\begin{array}{r}59 \cdot 5 \\
5 \cdot 0\end{array}$ & $\begin{array}{r}36 \cdot 4 \\
3 \cdot 8 \\
\end{array}$ & $?$ \\
\hline
\end{tabular}

*(a)-(b)

The major epidemic expected in 1968-9 thus failed to materialize, and the incidence in this period was typical of that in other interepidemic years.

The remaining sections of Table II are designed to answer the question whether this satisfactory finding was due solely to the prevention of measles in vaccinated children, or whether the vaccinations were numerous enough also to have prevented the disease spreading among those who were still susceptible. These sections of Table II present estimates of the proportion of children of different ages who were likely still to be susceptible to measles at the beginning of the period, and (derived from them) estimated notification rates of measles among susceptibles, as distinct from among the whole population.

The estimates of the percentages of the population who were susceptible at different ages in October 1966 and October 1967 are based on a mathematical model in which it is assumed that immunity to measles infection is complete for the first six months of life and that individual susceptibility increases rapidly above this age to a level of complete susceptibility from age 5 onwards. It is further assumed that $90 \%$ of the population will have contracted measles (and will have developed complete immunity therefrom) by the age of 15 years. (This is only one of several sets of arbitrary but plausible assumptions which have been studied and which lead to similar conclusions.)

Information on the attack rates of measles at different ages at different stages of a typical two-year cycle of measles incidence was derived from the Registrar General's tabulations of measles notifications during the 12 years 1956-67, with an allowance for undernotification. With this information, and the above assumptions, it is possible to trace through the experience of cohorts of children born at different stages of the two-vear cycle. This leads to the estimated percentages susceptible which are shown in Table II. For example, $98.6 \%$ of children aged 1 are estimated to be susceptible in the October preceding an epidemic year (fourth line of figures); after the evidemic, a year later, when they are aged 2 , only $83.3 \%$ are still susceptible (ninth line). On the other hand, $94.5 \%$ of those aged 1 are estimated to be susceptible in the October preceding an interepidemic year (ninth line) and a year later $90.6 \%$ are still susceptible (fourth line). With these Dercentages the estimated notification rates among susceptibles are readily calculated: for example, at age 2 in 1966-7 the estimate is 10.1 divided by 90.6 -that is, $11.1 \%$.

In 1968-9 the situation was different from that two years earlier because the numbers of susceptibles had been reduced bv the measles vaccinations. If it is assumed that onlv susceptible children were vaccinated (which is probably an overstatement) the percentages susceptible at the outset of the 1968-9 period will have been lower than those two years earlier by the percentages who were vaccinated. For example, at age 3 the estimate of $79.3 \%$ susceptible has been reduced to $67.7 \%$ susceptible, because $11.6 \%$ of children of this age had been vaccinated. If it is then further assumed that none of the vaccinated children contracted measles (which is certainly an overstatement) the final line of the Table gives the estimated percentages of susceptibles notified in 1968-9.

These figures are substantially lower than the corresponding figures for the epidemic two years earlier. In other words, the vaccinations not only protected the vaccinated children from measles but increased the numbers of immune children in the population enough to prevent measles spreading as an epidemic among the unvaccinated and susceptible children during 1968-9. In place of the expected epidemic in 1968-9 there was a second period of low incidence after the interepidemic period 1967-8.

\section{Discussion}

This analysis shows that the vaccination of about $10 \%$ of the child population against measles was sufficient, in epidemiological terms, to convert what would otherwise have been a potential "epidemic" situation in the country as a whole in October 1968 into an "interepidemic" situation. Ten per cent. may seem a surprisingly small proportion, but, as is shown in Table II, it was sufficient to alter the estimated percentages of susceptibles at different ages from pre-epidemic levels to values even lower than those normally occurring at the beginning of an interepidemic period. The small extent of the "swing" in the estimated proportions susceptible during the two-year cycle of measles in the country and, more generally, between the beginning and end of a measles epidemic, has been noted by several investigators (Stocks and Karn, 1928; Hedrich, 1933; I. Taylor, personal communication, 1969). The effectiveness of the measles vaccination campaign in suppressing the expected 1968-9 epidemic provides further confirmation of the small difference, in the country as a whole, between a situation which favours a high measles incidence and one which favours a low incidence. At the same time, Table I shows that though there was no general measles epidemic in 1968-9 there were some local epidemics (as in earlier interepidemic periods) and these occurred both in areas with little and with much previous measles vaccination. Presumablv in such areas the numbers of remaining susceptibles who had had neither measles nor vaccination previously, together with new births and susceptible unvaccinated migrants into the area, had allowed a build-up of susceptibles locally to a level which favoured an epidemic. 
In the past each interepidemic period has been followed by an epidemic period in this country, because the number of cases of measles which arose during the interepidemic period was relatively small and was insufficient to counterbalance the increase in susceptibles resulting from the annual births. As a consequence the proportions susceptible at different ages in the country as a whole had reverted to pre-epidemic levels by the following autumn. The same tendency will have applied after the unexpectedly low incidence of measles in 1968-9, which, as has been shown, represented a low incidence among susceptibles. Thus susceptibility percentages will have tended to increase by October 1969 to values approaching the October 1966 levels. On the other hand, there were further vaccinations, not taken account of in the analysis in Table II, before Wellcome vaccine was withdrawn in March 1969 (British Medical fournal, 1969), and these will have tended to decrease the susceptibility percentages, as will the relatively few vaccinations which were given between March and October 1969. The seasonal pattern of the measles notifications since October 1969 has been similar to that in previous interepidemic periods, with a peak during the early summer, but the figures during May, June, and July 1970 were unusually high. In August 1970 considerable publicity was given to these high figures, but by that time the notifications were already decreasing, as they have usually done in the past in the late summer, both in epidemic and in intorepidemic years.

The measles vaccination campaign in the whole country between the summer of 1968 and October 1969 was therefore intensive enough to have prevented the epidemic expected in 1968-9 and also to a large extent the epidemic which might otherwise have been expected to follow during 1969-70. The total number of children aged under 15 vaccinated against measles in 1968 and 1969 was 1,117,199 (Report, 1968, 1969). This represents 73 child vaccinations for every 100 births during these two years.

Without detailed information (which has unfortunately not been collected) on the numbers of vaccinations at different times and at different ages since mid-1968 it is impossible to assess whether the susceptibility levels by the summer of 1970 favnured a mainr enidemic during the period October 1970 to September 1971. Whatever the position then, however, vaccination aoginst measles began again on a large scale during August 1970. It now seems probable that these additional vaccinations have been enough to prevent the development of a major epidemic also during the winter of 1970-1. Nevertheless, the measles notifications throughout the last quarter of 1970 were running at more than twice the normal "interepidemic" level, and substantially above the levels reached during the autumn of 1968, following the initial stages of the national vaccination campaign.

\section{LONG-TERM CONTROL}

The effects of the measles vaccinations to date have therefore been at most a temporary "holding" operation, suppressing expected maior epidemics but leaving a substantial endemic incidence of the disease. It is of interest to make some estimate of the continuing level of vaccinations which would be necessary to maintain this situation-namely, freedom from major measles epidemics-more or less indefinitely. In the past the numbers of measles notifications have been of the order of 600,000 during epidemic periods and 200,000 during interepidemic periods, but it is known that a substantial proportion of measles cases, probably more than a third, are not notified (Benjamin and Gore, 1952; Bartlett, 1960). Thus the numbers of cases of measles have been of the order of $1,000,000$ and 350.000 in alternate years. If the susceptibility levels in the child podulation are to be maintained permanently at or below the levels characteristic of the begin- ning of an interepidemic period it will be necessary to "replace" the "excess" cases during each epidemic-namely, 650,000 cases of natural measles-by 650,000 artificially immunized susceptible subjects in the course of every two years. This represents the vaccination of 40 to $50 \%$ of the children born each year, allowing for the fact that some vaccinations will not confer immunity (M.R.C. Measles Vaccines Committee, 1971). Thus though the vaccination of about $10 \%$ of susceptibles just before an expected epidemic has been found to change the epidemic to an interepidemic situation, a much higher continuing level of vaccinations will be needed if the effect is to be more permanent.

It is not certain whether a vaccination programme of this intensity, if maintained for several years, would result simply in a continued steady incidence of 350,000 cases of measles a year. It is to be hoped that the effect would instead be an incidence falling steadily to lower and lower levels. It is, however, important to realize that the epidemiological stability of the former situation would be dependent on the immunity conferred on susceptibles by the 350,000 cases of natural measles each year. It follows that if, instead, the incidence of natural measles falls from year to year the effect will be a progressive rise in susceptibility to levels which would eventually favour a major epidemic-unless, of course, this tendency was compensated by an increase in the proportion of children vaccinated above the level of 40 to $50 \%$. It would then be questionable whether measles would succeed in eradicating itself from the community before the susceptibility levels again rose above a critiçal level or whether a further major epidemic would occur.

It is also worth considering whether, in a community which had freed itself from natural measles, it would be possible to prevent the reintroduction of the disease in a situation in which about half the child population and rising proportions of the adult population were susceptible to the disease. Since measles has been able to maintain itself in the past in this country in a situation in which, on average, about $45 \%$ of the child population (under 15 years) and virtually none of the adult population are susceptible to the disease, the importation of a small number of cases might at any time suffice to re-establish the disease. An air traveller who is incubating measles from a contact overseas may well show no symptoms until several days after arrival in this country, and the disease can be highly infectious for several days before it is diagnosed (Hope Simpson, 1948).

It would therefore seem virtually impossible nowadays to prevent the recurrence of the disease sooner or later in a population with susceptibility levels greater than those which currently permit measles to remain endemic with epidemics in alternate years. Indeed, vaccinations might have to be at least as numerous as the present numbers of cases of natural measles if the susceptibles were to be sufficiently scattered in the population for reintroduced measles not to gain a footing This would imnly a vaccination rate of the order of 80 to $90 \%$ of the children born each year.

Thus the control and eradication of measles and the subsequent maintenance of a measles-free community for an indefinite period would be a major undertaking. In view of the nearly complete susceptibility of uninfected subjects and the highly infectious character of measles its long-term control by vaccination will probably prove more difficult than for any other infectious disease.

We wish to thank the following medical officers of health and their staffs for their collaboration in the study of the community effects of measles vaccination in eight areas: Dr. A $R$ Buchan (Leicestershire), Dr. Margaret Glass (now retired) and Dr. J. G. M. Mortimer (Bedford), Dr. A. Hutchison (Kingston upon Hull), Dr. A. McGregor (Southampton), Dr. R. C. M. Pearson (now retired) and Dr. D. L. Wilson (Newcastle upon Tyne), Dr. W. 
Powell Phillips (Cardiff), Dr. J. F. Warin (Oxford), Dr. R. C. Wofinden (Bristol). The study in these eight areas was co-ordinated by Dr. C. L. Miller and Mrs. A. Allchin (Central Public Health Laboratory, Colindale).

We are also grateful to the members of the M.R.C. Measles Vaccines Committee for helpful comments on the draft of this report.

\section{References}

Bartlett, M. S. (1960). Fournal of the Royal Statistical Society, A, 123, 37 Benjamin, B., and Gore, A. T. (1952). British fournal of Social Medicine, 6, 197.

British Medical fournal, 1969, 1, 791.

Hedrich, A. W. (1933). American Fournal of Hygiene, 17, 613.

Hope Simpson, R. E. (1948). Lancet, 2, 755.

M.R.C. Measles Vaccines Committee (1971). Practitioner. In press.

Parry, W. H. and Ducksbury, C.F.J. (1970). Medical Officer, 124, 329

Report (1968). On the State of the Public Health. London, H.M.S.O

Report (1969). On the State of the Public Health. London, H.M.S.O

Stocks, P., and Karn, M. (1928). Annals of Eugenics, 3, 361.

\title{
Uterine Hypertonus during Labour Induced by Prostaglandins
}

\author{
G. ROBERTS, A. C. TURNBULL
}

British Medical fournal, 1971, 1, 702-705

\section{Summary}

Labour was induced successfully at or near term in 34 out of 35 cases by combined amniotomy and intravenous infusion of either prostaglandins $F_{2} \alpha, E_{2}$, or $E_{1}$. Of particular importance is the finding of hypertonus in 4 of the 18 cases induced with prostaglandin $\mathbf{E}_{2}$.

\section{Introduction}

Prostaglandins, a group of specialized hydroxy-fatty acids, have been shown to possess spasmogenic effects on human non-pregnant (Pickles et al., 1965) and pregnant myometrium (Embrey and Morrison, 1968). Bygdeman et al. (1968) showed that the $\mathrm{E}$ prostaglandins caused "unphysiological elevation of tonus" and thought that they were unsuitable for the induction of labour. More recently, however, they have been used successfully to induce labour at or near term, without hypertonus (Embrey, 1970; Karim et al., 1970). As relatively few centres are investigating the clinical applications of prostaglandin administration, the experience in Cardiff is presented of the intravenous infusion of prostaglandins $F_{2} \alpha, E_{2}$, and $E_{1}$ for induction of labour, with particular emphasis on the incidence of uterine hypertonus during administration of prostaglandin $\mathrm{E}_{2}$.

\section{Patients and Methods}

Patients chosen for study were those in whom induction of labour was required because of the obstetric conditions shown in the Table. The state of the cervix was assessed and classified according to the criteria of Embrey and Anselmo (1962). After amniotomy the uterine activity was recorded by measuring intra-amniotic pressure changes by means of an open-ended saline-filled catheter inserted into the uterus with the aid of a modified Drew Smythe catheter. The fluid-filled catheter was then connected to a Sanborn 267 AC pressure

\footnotetext{
Department of Obstetrics and Gynaecolosy, Welsh National School of Medicine, Cardiff CF2 1XF

G. ROBERTS, M.B., M.R.C.O.G., Senior Registrar (Present address: St. David's Hospital, Cardiff CF1 9TZ)

A. C. TURNBULL, M.D., F.R.C.o.G., Professor
}

transducer and the tracings were recorded by means of a Hewlett-Packard 7712 amplifier and recorder.

Spontaneous uterine activity was observed for one hour before the intravenous infusion of sterile solutions of either prostaglandins $\mathrm{F}_{2} \alpha, \mathrm{E}_{2}$, or $\mathrm{E}_{1}$. Patients showing strong stimulatory uterine effects after amniotomy alone were excluded from the study. The prostaglandins, which had been previously diluted in ethanol $(0.5 \mathrm{mg} / \mathrm{ml})$ and stored at $-20^{\circ} \mathrm{C}$, were further diluted with iso-osmotic saline before being administered by means of a Palmer continuous 'slow injector. The maternal pulse rate, blood pressure, and fetal heart rates were recorded frequently.

For prostaglandin $F_{2} \alpha$ an infusion rate of $3 \mu \mathrm{g} / \mathrm{min}$ was used initially and doubled when necessary to obtain optimum uterine activity. In the earlier cases induced with prostaglandin $E_{2}$ an initial infusion rate of $3 \mu \mathrm{g} / \mathrm{min}$ was also used, but with experience smaller doses were often found to be effective $(0.75-1.5 \mu \mathrm{g} / \mathrm{min})$. At first the infusions were usually continued until the patient delivered, but as the study progressed it was found that the infusion could be discontinued when labour was well established. The type of prostaglandin used in each individual was determined by its availability at the time rather than by random selection. Prostaglandin $F_{2} \alpha$ was used in seven patients, $E_{2}$ in 18 , and $E_{1}$ in 10.

In the group studied (see Table) 11 were primigravid patients and 13 were of parity 3 or greater. The physical state of the cervix was noted to be unfavourable in 10 cases intermediate in 19, and favourable in 6.

A constant feature of our intravenous infusion of prostaglandins has been the development of a "red line" over the course of the vein from the site of the cannula, and some patients have complained of severe pain in the forearm or shoulder on the same side as the infusion but distant from the cannula in the vein.

\section{Results}

Induction of labour was successful in 34 out of 35 cases; all patients successfully induced delivered within $13 \frac{1}{2}$ hours. The latent period between the start of the infusion and the onset of stimulated uterine activity ranged from 20 to 40 minutes with prostaglandin $\mathrm{F}_{2} \alpha$, but with the $\mathrm{E}$ prostaglandins the latent period was much shorter, about 10 minutes on average. In agreement with the findings of other workers, $E$ prostaglandins were found to be more potent oxytocics than $F_{2} \alpha$, and the $\mathrm{E}$ compounds could effectively induce labour in smaller doses than prostaglandin $F_{2} \alpha$. 